\title{
KNOWLEDGE AND PREDICAMENTS OF GENDER-BASED VIOLENCE IN SOUTHWEST NIGERIA
}

\author{
Dominic E. Azuh ${ }^{1 \star}$, Matthew. E. Egharevba ${ }^{2}$, Akunna E. Azuh ${ }^{3}$, Olusegun P. Olaoye ${ }^{4}$, \\ Enoch O. Alabi ${ }^{5}$ \\ ${ }^{1}$ Department of Economics and Development Studies, Covenant University, Ota, Ogun State, \\ Nigeria, dominic.azuh@covenantuniversity.edu.ng \\ ${ }^{2}$ Department of Sociology, Covenant University, Ota, Ogun State, Nigeria \\ ${ }^{3}$ Department of Business Management, Covenant University, Ota, Ogun State, Nigeria \\ ${ }^{4}$ Academic Planning Unit, Covenant University, Ota, Ogun State, Nigeria \\ ${ }^{5}$ CUCRID, Covenant University, Ota, Ogun State Nigeria \\ ${ }^{*}$ Corresponding Author
}

\begin{abstract}
Over time, the ideals and provisions of laws and values that emphasize equity, mutual respect, social justice, equal opportunity for both gender leave much to be desired, particularly among sub-Saharan African countries, including Nigeria. The incidence of domestic violence (DV) in Nigeria is generating widespread concern, given the growing cases of rape, battery/beating, sexual harassment, and all sorts of sexual molestations. The study objective was to identify determinants of domestic violence in the study area and recommend how to curb this obnoxious practice. Women residing in randomly selected wards in Somolu Local Government Area of Lagos State formed the respondents and survey assisted by community informants. Both questionnaire and focus group discussions methods were employed to generate data. The findings depict that both ever had sex against the will $(P=0.005)$ and partners under frequent stress $(P=$ 0.000 ) had significant relationship with the dependent variable (ever beaten by spouse). The study recommends women's education beyond the secondary level to empower them, job opportunity for men to reduce stress levels among partners, and accelerated community awareness towards reducing DV incidence among communities in the study area.
\end{abstract}

Keywords: Domestic violence, women, gender, empowerment, Nigeria

\section{INTRODUCTION}

Mitigation of domestic violence entails understanding the problem and developing appropriate policies for persons affected. Domestic violence (DV) against women is a health and universal problem occurring in every society which retards the achievement of developmental goals (UNIFEM and United Nation Development Fund 2010). It is the most ubiquitous particularly in developing countries, including Nigeria 
where patrirchial system is being practice. According to Egharevba (2016), DV is a wedge against women's better quality of life and contributing their quota to national development leading to non-realization of Sustainable Development Goals (SDGs), particularly goal numbers 5 (Gender Equality) and 10 (Reduced Inequalities). It is an epidemic of global proportion that has a devastating and far-reaching impact on economic growth, poverty, and other women's developmental activities. According to Khan (2015), domestic violence against women is a gross pervasive violation of their human rights and a severe impediment towards realizing women's potentials and contributions of their quota to development.

Domestic violence issues have attracted global attention and national concern for over four decades. For instance, been at the forefront of international summits, mostly in line with gender equality. For instance, the U.N. Convention on the Elimination of All Forms of Discrimination Against Women 1979, International Conference on Population and Development 1994, The Beijing Platform for Action, at the Fourth World Conference on Women in 1995 and 1993 Vienna Declaration on Human Rights. All called for equal rights for men and women empowerment of women, and women's quality health care, including family planning services; and protected from discrimination/violence. At the national level, we have the Constitution of the Federal Republic of Nigeria 1999, Criminal Code and Penal Code Laws of Nigeria, Customary Laws and practices, and the police Act. Domestic violence has a strong bearing on development, as half of the population of Nigeria are women (NPC, 2009), who are denied of their contribution towards economic growth and national development through various forms of domestic violence.

DV is aggravated by inequality, poverty, low socioeconomic status, women's economic helplessness, subjugation, low political will, dependency on men, the prevailing culture of violence and conflict, discriminatory national laws, insufficient literacy levels, "culture of silence," and the subordinate status of women in society.According to Olawole et al (2018), poor inter-spousal communication is one of the measures of gender inequity. Azuh et al. (2014) found that the main factors militating against women's high status are poor socioeconomic, demographic and cultural practices, and violence against women. The sociocultural practices (like female genital mutilation, male dominance, customary laws, wife's economic dependency, subjugation, and other traditional gender norms) accelerate domestic violence, among others (Azuh, 2000). For instance, the NDHS survey report revealed that among women age $15-49,31 \%$ have experienced physical violence, $9 \%$ experienced sexual violence and $6 \%$ of women experienced physical violence during pregnancy (NPC, 2019). While Martin et al. (2007) similarly reported that DV contributes to maternal deaths, Campbell (2002) observed domestic violence associated with a host of reproductive health problems. Domestic violence is one of the crucial appendages of gender inequality, undermines human and economic development (Azuh et al., 2017b).

Nigeria has not done much towards ending domestic violence cases, as domestic violence cases are still increasing. In Nigeria, stories abound on abuse of women by their partners ranging from the acid bath, setting of wife ablaze following a minor argument, man butchering wife, and wives in various incidences of rituals. Women's lives in Nigeria have been profoundly affected by domestic violence, which ruthlessly deprives women of their status and dignity in every sphere of life. This situation is encouraged by suppressive and inconvenient customs and traditions. It is disheartening to note that studies of this nature have not been vigorously pursued, particularly in rural communities (Annan, 2008), leading to insufficient knowledge/understanding of the DV and its implications. Hence, the current study will throw more insight into domestic violence in the study area and other wards and local government areas. The study is not only on sexual issues, it tried to examine few other forms of DV such as respondent beating (physical abuse), belittle of the respondent in the presence of others, and fear to sought help when DV occurred, permission to carry out one's activity and non-participation in household decision making. Hence, the study aimed at identify determinants of domestic violence in the study area and recommend how to curb this obnoxious practice.

\section{METHODOLOGY}

A cross-sectional study of women residing in randomly selected wards in Somolu Local Government Area (SLGA) of Lagos State formed the survey respondents. The study employed a multistage design, and Somolu LGA was selected purposively in the first stage out of 20 Local Government Areas in the State. In the second stage, all the 13 wards in the study area were listed. At random, six wards were selected, consisting of Onipanu, Bajulaiye, Igboni/Fadeyi (Constituency - 1), Bariga, Ilaje/Akoka, and Gbagada Phase1/Obanikoro (Constituency - 11).

After that, all the households where women experienced domestic violence were identified with the assistance of community informants and interviewed. Eligible respondents were married females, divorced or separated spouses within the age bracket of 15-45 years, and experienced domestic violence. Where there was more than one eligible respondent in a family, one was randomly selected. Due to the study's culture, 
sensitivity, and unique nature, the researchers engaged community informants (C.I.s) to identify affected families for interview by experience and trained research assistants who maintained good rapport with the respondents and ethically collected information.

The survey method involved the use of a structured questionnaire as the instrument of the study. Information on the social and demographic characteristics and questions that would facilitate the realization of the study's objectives were all included in the survey instrument. The internal consistency (reliability) and construct validity of the device were affected through the Cronbach Alpha index, which yielded 0.65, by a psychologist and demographer, respectively. The data collection instrument was pre-tested, and the researchers carried out necessary modifications to perfect the tool. Most of the questions in the questionnaire instrument were adapted based on the questions of the Nigeria Demographic and Health Survey 2018 survey. Data were analyzed using a statistical package for social sciences software version 19.0. On the whole, 162 respondents constituted the sample size. In addition to the quantitative data, focus group discussions (FGDs) were conducted among selected women associated with domestic violence in the study area. The FGDs data were analyzed using the thematic content analysis technique, which was done by categorizing the recurrent themes identified in each participant's responses.

\section{RESULTS}

\subsection{Socio-Demographic Characteristics of Respondents And Spouses}

Table 1 shows the demographic and social characteristics of the women interviewed in the study area. The age of respondents was highest between ages 15 - 29 years, with a proportion of $46.3 \%$ (see Table 1). The occupational status of the respondents interviewed ranged from full-time homemakers (18.5\%), unskilled labor $(25.9 \%)$, skilled artisans (17.9\%), and traders $(24.1 \%)$ to civil servants $(13.6 \%)$. Concerning spouse occupation, it ranged from unemployed (12.3\%), unskilled labor (18.5\%), skilled artisans (19.8\%), and traders $(27.8 \%)$ to civil servants $(21.6 \%)$. The highest level of education among respondents interviewed was secondary education (36.4\%), followed by primary education (24.7\%). However, respondents with no school and with post-secondary education accounted for $17.9 \%$ and $21 \%$, respectively. When reference was made to the education of their spouses, a similar but higher proportion had secondary level education (40.1\%), followed by those who attained post-secondary education (29\%). Nevertheless, respondents who had only primary education registered $19.8 \%$, and those who never went to school accounted for the tiniest proportion $(11.1 \%)$. Poverty was observed to be high in the study location, with $64.8 \%$ of the respondents fall under the poor social class.

Table 1 Socio-Demographic Characteristics of Respondents and Spouse

$\mathrm{N}=162$

\begin{tabular}{|l|l|l|l|l|l|l|}
\hline Age (Years) & Number & percent & Educational Attainment & Number & percent \\
\hline $15-29$ & 75 & 46.3 & No Formal Education & 29 & 17.9 \\
\hline $30-39$ & 47 & 29.0 & & Primary level & 40 & 24.7 \\
\hline $40-49$ & 29 & 17.9 & Secondary level & 59 & 36.4 \\
\hline 50 and above & 11 & 6.8 & & Post-secondary level & 34 & 21.0 \\
\hline & & & & & & \\
\hline Occupational Status & & & Spouse's Edu Attainment & & \\
\hline Fulltime Housewife & 30 & 18.5 & No Formal Education & 18 & 11.1 \\
\hline Unskilled Workers & 42 & 25.9 & Primary level & 32 & 19.8 \\
\hline Skilled Workers & 29 & 17.9 & Secondary level & 65 & 40.1 \\
\hline Trading & 39 & 24.1 & & Post-secondary level & 47 & 29.0 \\
\hline Civil Service & 22 & 13.6 & & & & \\
\hline & & & & & & \\
\hline Spouse's Occupation & & & & Social Class of \\
& 20 & 12.3 & Uespondent & & \\
\hline Unemployed & 30 & 18.5 & Middle Class & 20 & 12.4 \\
\hline Unskilled Workers & 32 & 19,8 & Lower Class & 37 & 22.8 \\
\hline Artisan & 45 & 27.8 & & & & 64.8 \\
\hline Trading & 35 & 21.6 & & & & \\
\hline Civil Service & & & & \\
\hline
\end{tabular}

Source: Authors' Compilation 2017 


\subsection{Factors Influencing Domestic Violence in the Study Area}

Factors influencing domestic violence in the study area (see Table 2) showed fascinating results. Vast majority of the respondents (82.7\%) consented to the understanding of domestic violence, and an incidentally huge proportion of $67.3 \%$ of respondents had sex against their will. A substantial proportion agreed willingly (32.7\%). This scenario manifests in obtaining permission in almost every activity of respondents, as seen in permission to visit family members or friends $(80.2 \%)$ and low participation in household decision making (27.8\%), respectively. Consumption of alcohol was examined as a factor in inducing domestic violence. Drunkards subject themselves below normal reasoning, and being under the influence of alcohol impairs judgment which orchestrates violence in homes. Spouse's alcohol consumption showed that above three-fifths of the respondents $(63.6 \%)$ stated that their spouses take a drink. However, a good proportion of respondents (36.4\%) responded contrary to alcohol consumption in the study area.

Table 2 Factors Influencing Domestic Violence

$\mathrm{N}=162$

\begin{tabular}{|c|c|c|c|c|c|}
\hline Variable & Number & Percent & Variable & Number & Percent \\
\hline $\begin{array}{l}\text { Awareness of Domestic } \\
\text { Violence }\end{array}$ & & & Ever Beaten by Spouse & & \\
\hline Aware & 134 & 82.7 & Yes & 125 & 77.2 \\
\hline Not Aware & 28 & 17.3 & No & 37 & 22.8 \\
\hline Ever Had Sex against Will & & & Ever Sought Help & & \\
\hline Yes & 109 & 67.3 & Never told Anyone & 92 & 56.8 \\
\hline \multirow[t]{3}{*}{ No } & 53 & 32.7 & Friends & 41 & 25.3 \\
\hline & & & Family Members & 22 & 13.6 \\
\hline & & & Police & 7 & 4.3 \\
\hline $\begin{array}{l}\text { Need Permission to Visit } \\
\text { Family Members/Friends }\end{array}$ & & & $\begin{array}{l}\text { Spouse's Violent } \\
\text { Childhood }\end{array}$ & & \\
\hline Yes & 130 & 80.2 & Yes & 98 & 60.5 \\
\hline No & 32 & 19.8 & No & 64 & 39.5 \\
\hline $\begin{array}{l}\text { Participation in } \\
\text { Household Decision- } \\
\text { making }\end{array}$ & & & $\begin{array}{l}\text { Ever Belittled in the } \\
\text { presence of Others }\end{array}$ & & \\
\hline Yes & 45 & 27.8 & Yes & 89 & 54.9 \\
\hline No & 117 & 72.2 & No & 73 & 45.1 \\
\hline $\begin{array}{l}\text { Spouse's Consumption of } \\
\text { Alcohol }\end{array}$ & & & $\begin{array}{l}\text { Partner's under } \\
\text { Frequent Stress }\end{array}$ & & \\
\hline Yes & 103 & 63.6 & Yes & 109 & 67.3 \\
\hline No & 59 & 36.4 & No & 53 & 32.7 \\
\hline
\end{tabular}

Source: Authors' Compilation 2017

The incidence of physical abuse of women is very high in the study area as respondents ever beaten by their spouses registered an enormous proportion $(77.2 \%)$, and those in the never category are less to the tune of slightly one-fouth $(22.8 \%)$. On examination of ever sought help among the respondents, we observed that above half of the proportion never let out their state to anybody (56.8\%). While a substantial number of them $(25.3 \%)$ told close friends, 13.6 percent could let their family members know that they were under severe bondage. Nevertheless, an insignificant proportion (4.3\%) could muster the courage to inform the law enforcement agency (Police) even though nothing might have happened to the abuser. According to spouse's childhood violent status, an examination of respondents showed that slightly above three-fifths of the respondents $(60.5 \%)$ noted that their spouses had been abused during childhood, whereas $39.5 \%$ stated on the contrary.

Emotional violence is a profound act that affects women tremendously and creates an unforgettable ugly memory in them. One of the emotional violence considered in the current study was ever belittled in the 
presence of others. The study showed that over half of respondents $(54.9 \%)$ confessed that their spouses criticized them in public. A substantial proportion of them $(45.2 \%)$ consented to be free from this practice. Partner's stress level affects domestic violence. The result showed that above three-fifths of the study respondents (67.3\%) agreed that their spouses were under frequent stress, whereas a lower proportion $(32.7 \%)$ of them stated otherwise. The analysis of variance (ANOVA) (see Table 3 ) was another test to support the earlier univariate analysis of DV. The multivariate analysis also showed a significant relationship between ever had sex against the will $(P=0.005)$ and Partner under frequent stress $(P=0.000)$ and the dependent variable (ever beaten by a spouse).

Table 3 Regression Analysis - ANOVA

\begin{tabular}{|l|l|l|l|l|l|l|}
\hline \multicolumn{2}{|l|}{ Model } & $\begin{array}{l}\text { Sum of } \\
\text { Squares }\end{array}$ & df & $\begin{array}{l}\text { Mean } \\
\text { Square }\end{array}$ & F & Sig. \\
\hline \multirow{3}{*}{} & Regression & 92.061 & 2 & 46.031 & 73.942 & .000 \\
\cline { 2 - 8 } & Residual & 197.964 & 318 & .623 & & \\
\cline { 2 - 7 } & Total & 290.025 & 320 & & & \\
\hline
\end{tabular}

a. Dependent Variable: Ever beaten by Spouse

b. Predictors: (Constant), Ever had sex against will, Partner's under frequent stress

\section{Coefficients}

\begin{tabular}{|c|c|c|c|c|c|c|}
\hline \multirow{2}{*}{\multicolumn{2}{|c|}{ Model }} & \multicolumn{2}{|c|}{$\begin{array}{l}\text { Unstandardized } \\
\text { Coefficients }\end{array}$} & \multirow{2}{*}{$\begin{array}{l}\text { Standardized } \\
\text { Coefficients } \\
\text { Beta } \\
\end{array}$} & \multirow[b]{2}{*}{$\mathrm{t}$} & \multirow[b]{2}{*}{ Sig. } \\
\hline & & $B$ & Std. Error & & & \\
\hline & (Constant) & 2.968 & .193 & & 15.407 & .000 \\
\hline & $\begin{array}{l}\text { Ever had sex } \\
\text { against will }\end{array}$ & .132 & .050 & .123 & 2.652 & .005 \\
\hline & $\begin{array}{l}\text { Partner's under } \\
\text { frequent stress }\end{array}$ & -.489 & .042 & -.543 & -11.707 & .000 \\
\hline
\end{tabular}

a. Dependent Variable: Ever beaten by Spouse

\section{The report on FGDs is presented below:}

\section{Awareness of domestic violence problem and help-seeking}

No doubt majority of participants (91.4\%) knew domestic violence, but this has not enhanced institutional reporting or disclosure of its incidence to police/law enforcement agencies. In addition, seeking help by respondents is exceptionally very poor as 56.8 percent never told anyone or sought help, whereas an insignificant proportion (4.3\%) said the police in the study area. FGDs also supported this claim. The theme derived is that the fear of being beaten or thrown out engengers low seeking of help by women abused by husbands/partners.

"The problem of domestic violence is too much, and we cannot tell anyone because my lord (husband) will throw me out, and no one in this area will help me. Sometimes we get so many beatings, and neighbors do not come to my rescue. One time my friend in this neighborhood gets beaten by her husband when pregnancy and baby came out, and she never seeks help or tells police because nothing will happen". (Participant, 40 years).

\section{Another participant divulged}

"My Husband always had sexual intercourse against my will, saying it is his full right and nothing can stop him. He kicked me badly on few times. He forced me to have sex, and if I cannot resist. He also threatens to throw me out, and I cannot say no." (Participant, 36 years).

Another participant validates the above statement

"Our culture made them (their husbands) heads and whatever they say we must obey. No one can question their authority. Our husbands control us and permit us to go out even to visit our family people or female friends." (Participant, 44 years). 


\section{On husbands' right to treat their wives anyhow}

Husbands believe that they are head of households bestowed with the powers to control and treat their wives as they like. Husbands' authority knows no bounds, and whatever they do is accepted in society a patriarchal society like Nigeria. They halt the feelings of their wives, dehumanized and belittle them in the presence of others with ease, as seen in Table 2, where $54.9 \%$ of wives were criticized in the face of others.

"Our daddies (husbands) most times hurt our feelings by belittling us in the presence of others without considering our feelings. They shout at us and say or do anything without minding who is there. I remember one woman living in my place her husband brought his lady friend often to the house and ask her to serve both of them food otherwise she will go back to her father's house" (Participant, 37 years).

"My husband consumes alcohol like water, and I tried so many times to stop him, but he refuses and still drinks too much. One day I hide his drink, and he beat me too much." (Participant, 33 years).

In line with the above assertion, a participant speedily adds. "If my husband drinks, he will beat me too much that day" (Participant, 40 years).

A participant concurs that

"Sometimes my husband will order that I should give him feeding money to go and drink alcohol and I obey to avoid being beaten or other problems" (Participant, 38 years).

The involvement of partners in household decision-making represents accommodation and low power and control by husbands. The theme derived is that the more power and control hungry a husband is, the more restriction he places on the wife.

When asked participants about their level of participation in household decision making, one of them said

"My husband has never involved me in the household decision-making. Rather he comes and dishes out activities. One sees what he does like that, and his partner's opinion not solicited and whatever money you get for food and housework is only his decision". (Participant, 43 years).

Another participant revealed a contrary view

"My husband involve me in selected household decision making issues though not always" (Participant, 45 years).

\section{DISCUSSION}

Women's rights are still being violated in physical assault, sexual assault, economic exploitation, widowhood, and inheritance sharing (Okunola and Ojo, 2012). The study showed a high proportion of young age among the respondents. Age could be a risk factor in domestic violence as the young age of respondents might depict lack of education or low education and lack of paying job outside the home or full housewife status, leading to low social class and dependency on husband, which had been noted by earlier studies (Bachman and Saltzman 1995; Ratner, 1993). The general education of respondents was lower (secondary and postsecondary education) (57.4\%) compared to their spouses (69.1\%), respectively, which aligns with earlier studies (Antai and Antai, 2008; Azuh et al., 2017a). In the study area, above three-fourths of respondents $(77.2 \%)$ reported being beaten by their spouses even though most were aware $(82.7 \%)$ of domestic violence, as noticed in both table 2 and FGD participants. These were equally in line with an earlier reported survey (NPC, 2014; NPC 2019).

Forcing a woman to have sex against her will, obtaining permission to visit parents/family members, not participating in household decision-making, and belittling her in the presence of others are various forms of DV. Control and subjugation lead to dangerous emotional consequences such as trauma, depression among health issues. In addition, women entrapped in this type of slavery situation find it difficult to make any meaningful contribution to the economy and society. Respondent's dependency on the spouse might further aggravate DV. Hence, there is a need to eliminate the suppression of our women due to domestic violence through public enlightenment, especially of the menfolk and empowerment of women.

\section{CONCLUSION}

DV in Nigeria is more or less a private affair that rarely draws public attention, so any form of DV is not seen as grave matter in society. Due to the patriarchal nature of the community, no one condemns the perpetrator of such hideous crimes. The results of regression analysis and the thematic observations from FGD also confirm DV in the study area. It is a multifaceted problem, and though some researchers have undertaken 
related studies, the extent remains unacceptable. Hence, more investigation like the current one is needed to explore the factors influencing domestic violence and evolve informed policy implications. Therefore, the study recommends women's education beyond the secondary level, female empowerment and mass public awareness campaigns mainly targeted at menfolk. In addition, the enforcement agency should be established and empowered to deal decisively with culprits of DV.

\section{LIMITATIONS}

Not many respondents were willing to give their consent, as many refused due to fear of their spouse and identification as a victim of DV.

\section{ETHICS}

The ethical principles were adhered to during the cause of the study. Rearchers obtained verbal consent of respondents before the administration of the questionnaire in which the exercise took place secluded place. In addition, free choice participants and at-will withdrawal existed. Also, the study maintained a high-level confidentiality position as the issue is a society-sensitive type.

\section{ACKNOWLEDGMENT}

The authors appreciate respondents, participants, community informants, resilient interviewers for their cooperation. In addition, they acknowledge Covenant University Center for Research, Innovation, and Discovery for supporting this publication.

\section{REFERENCE LIST}

Allen-Davis J. (2011). Kaiser permanent national diversity council and permanent national diversity office (women's health). Provider's handbook on culturally competent care: Kaiser permanent 1st edition.

Azuh, D. E., Azuh, A. E., Iweala, E. J., Adeloye, D., Akanbi, M., \& Mordi, R. C. (2017a). Factors influencing maternal mortality among rural communities in southwestern Nigeria. International Journal of Women's Health, 9, 179-188.

Azuh, D., Amodu, L., Azuh, A. E., Toluwalope, O. and Matthew, A. O. (2017b). Factors of Gender Inequality and Development among Selected Low Human Development Countries in sub Saharan Countries. IOSR Journal of Humanities and Social Science. Vol. 22 Issue 2 Ver. Iv. Pp. 1-7.

Azuh, D., Egharevba, D. E. and Azuh, Akunna E. (2014). Gender Discrimination and National Politics: The Nigerian Case. Covenant University Journal of Politics and International Affairs, vol 2 No. 2, pp. 19-30.

Azuh, D. (2000). Cultural Practices and the Spread of AIDS in Nigeria. In K. Mahadevan et al (ed.) Reproductive Health of Humankind in Asia and Africa: A Global Perspective. Delhi: B. R. Publishing Corporation. Volume 1, 249-268.

Antai, D. E. and Antai, J. B. (2008). Attitudes of women toward intimate partner violence: a study of rural women in Nigeria. Rural-remote-health-2008-8(3):996

Bachman R, Saltzman L. E. (1995) Violence against women: estimates from the redesigned survey. Washington: Bureau of Justice Statistics, National Institute of Justice.

Egharevba, M. E. and Eguavoen, A. and Azuh, Dominic E., Iruonagbe, C. T. and Chiazor, A.I. (2016). Microfinance and Poverty Reduction Strategy for Promoting National Development: The Challenge of Social/Financial Inclusion. The Social Sciences, Vol.11 (22), 5373-5386.

Khan, Anisur Rahman (2015). A Chronicle of the Global Movement to Combat Violence against Women: The Role of the Second-Wave Feminist Movement and the United Nations: The Perspective of Bangladesh. Journal of International Women's Studies, 16(2),213-244.

Martin SL, Macy RJ, Sullivan K, Magee ML (2007) Pregnancy-associated violent deaths: The role of intimate partner violence. Trauma, Violence, \& Abuse 8: 135-148.

National Population Commission (NPC) 2014. Nigeria Demographic and Health Survey 2013. Abuja: National Population Commission and ORC Macro.

National Population Commission [NPC] (2009). 2006 Population and Housing Census of the Federal Republic of Nigeria. Priority Tables. Volume 1. Abuja: National Population Commission. 
Okunola, Rashidi Akanji and Ojo, Matthias Olufemi Dada (2012). Violence against Women: A Study of Ikirearea of Osun State Nigeria. African Journal of Social Sciences, Volume 2 Number 2, 131-147.

Olawole-Isaac, A., Oni, G.A., Oladosun, M., Amoo, E.O. (2018). Inter-spousal communication: A means for achieving concordant fertility goals. Etude de la Population Africaine, 32(1), pp. 4068-4079.

Ratner P. A. The incidence of wife abuse and mental health status in abused wives in Edmonton, Alberta. Can J Public Health 1993; 83: 246-49.

UNICEF (2005) Violence at home (archive) Voices of Youth Forum. Retrieved Oct. 2008 from http://www.unicef.org/roy/discussions/archieve/index.

UNIFEM and United Nation Development Fund (2010). For Women Ending Violence against Women and Girls Programming Essentials, cited in Agumasie Semahegn, Tefera Belachew, Misra 